\title{
Российский рынок контрактного производства глазами одного из его участников
}

\section{Рассказывает генеральный директор ООО «ПСБ технологии»}

\section{А. Б. Соболев}

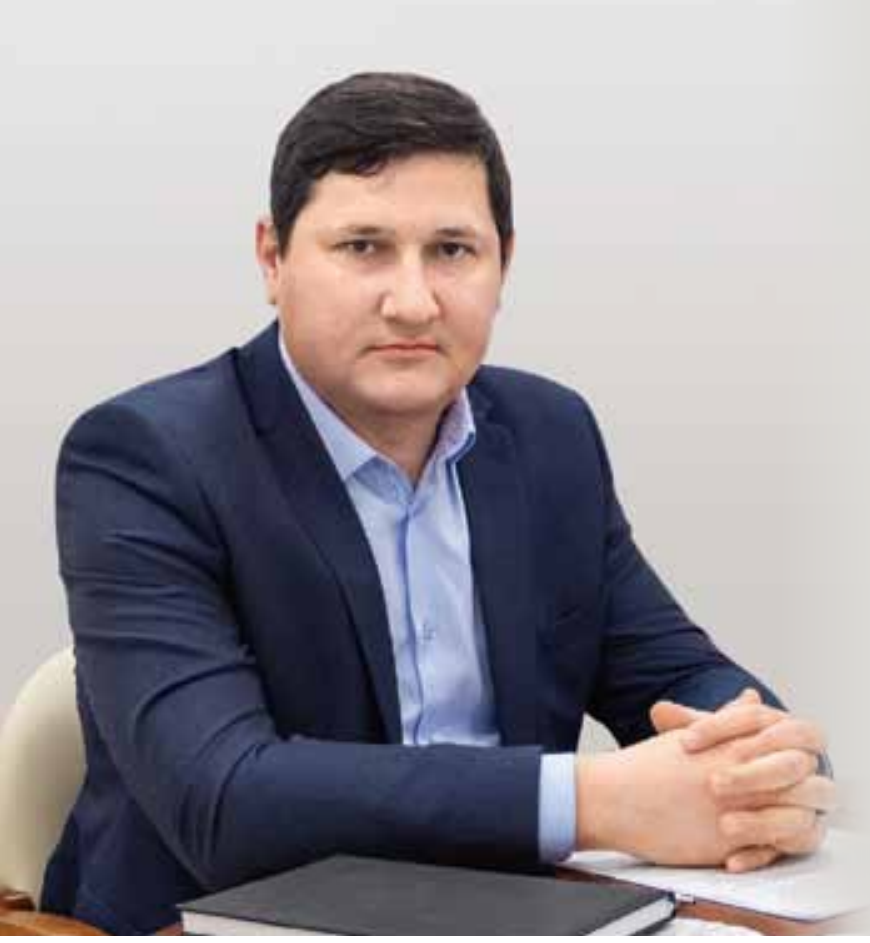

ООО "ПСБ технологии" - хорошо известный в стране контрактный сборщик электронных устройств, предоставляющий также услуги дизайн-центра по проектированию печатных узлов и плат для них. В этом году компания впервые продемонстрировала свои возможности широкому кругу европейских специалистов, приняв участие в международной выставке Embedded World 2020. О значимых для компании результатах выставки, а также о ситуации с контрактной сборкой в России, о продвижении контрактного проектирования, о локализации продукции зарубежных производителей и своем взгляде на меры государственной поддержки нам рассказал генеральный директор ООО "ПСБ технологии" Александр Борисович Соболев.

Александр Борисович, в прошедшем феврале ваша компания приняла участие в выставке Embedded World 2020 в Нюрнберге. Какие цели вы ставили перед собой, как оцениваете результаты? Каковы ваши впечатления от выставки в целом?

В этом году выставка, к сожалению, оказалась не столь многолюдной, как ожидалось: некоторые экспоненты в последний момент отказались от участия, и посетителей было меньше, чем могло бы быть. Тем не менее она произвела хорошее впечатление. Это одна из крупнейших выставок для представителей нашей области деятельности, и там, конечно, было показано много интересных разработок

Мы располагались на стенде Made in Russia в соседстве с примерно пятнадцатью другими российскими компаниями. Для нас это был первый опыт участия в зарубежных мероприятиях такого типа и масштаба, и я считаю его успешным: проведено около пятидесяти переговоров, чаще коротких на ногах, и некоторые из них имеют перспективу продолжения и перехода в русло практического сотрудничества.

Мы выбрали для продвижения на международной выставке три направления деятельности: дизайн печатных плат силами нашего дизайн-бюро, изготовление опытных образцов электронных узлов и локализацию производства продукции зарубежных компаний в России.

Первое направление было встречено с определенным интересом, мы обменялись контактами с несколькими подобными нам компаниями-разработчиками. Здесь может получиться что-то реальное.

Что касается изготовления прототипов, то в этой области нам будет сложно конкурировать с местными производителями. В Европе всё это идеально налажено. Те же компоненты - они всегда есть, а если какая-то позиция отсутствует, то ее привезут из США на следующий день после заказа.

Нам далеко до такого совершенства. Комплектацию для изделия можно собрать в лучшем случае за 
неделю - и это только то, что находится на складах поставщиков в России. Доля такой комплектации составляет обычно от 50 до 70\% позиций спецификации, остальное нужно завозить из-за границы, а это уже минимум две недели. Поэтому мы пришли к выводу, что изготовление опытных образцов для европейского рынка в настоящее время неперспективно.

Серьезный интерес потенциальных заказчиков вызвало третье направление - локализация производства. Здесь особенную активность проявили русскоязычные бизнесмены, живущие в Германии, Франции. Выгода понятна: если не импортировать, а собирать в России, то не надо платить пошлины; да и рабочая сила у нас сравнительно недорогая. Правда, с точки зрения последнего фактора мы имеем конкурентов в лице стран Восточной Европы - Румыния, Болгария, Македония также предлагают услуги по контрактной сборке достаточно дешево.

Как бы то ни было, при работе для российского потребителя наши позиции выглядят очевидно предпочтительными. Я говорю не о массовом производстве, а о небольших сериях, от сотен до нескольких тысяч изделий. Здесь мы способны обеспечить хорошее качество, сроки и сервис при конкурентных ценах. При этом мы ориентируемся на сложные проекты. Это промышленные компьютеры, медицинская техника и т.д.; модули нашего производства стоят на космических аппаратах, других ответственных объектах. Всё это было показано на выставке, и мы уже имеем несколько запросов на более подробные переговоры. Как раз сегодня пришел запрос из Франции; ведем переписку с Нигерией, у них тоже возникла заинтересованность в сотрудничестве.

Как сказываются на локализации проблемы с электронной компонентной базой (ЭКБ), о которых вы упомянули применительно к изготовлению прототипов?

В этом случае сроки не такие сжатые, работа идет по плану. Есть крупные поставщики, предлагающие хорошие цены, а нам, как контрактникам, еще и с дисконтом. Так что для задачи локализации производства комплектация не является принципиальной проблемой.

Когда вы локализуете производство изделий зарубежных заказчиков, требуют ли они сертификации вашей производственной базы по их нормам, или, наоборот, они должны сертифицировать свою продукцию по российским требованиям?

Это задача заказчика. Мы предлагаем ему наши возможности, а он сам определяет, что ему нужно просто снижение издержек за счет меньших затрат на сборку или полноценная локализация, открывающая перспективу участия в крупных программах с бюджетным финансированием.

С нашей стороны все необходимое уже обеспечено. Производство имеет сертификаты по отечественным стандартам и ISO 9001, мы состоим в списке отечественных производителей, и одно изделие уже прошло через наше производство в качестве локализованного. Имея опыт в подготовке необходимого комплекта документов для Минпромторга России, мы можем помочь заказчику и в организационном аспекте процесса локализации.

Стоит еще отметить, что заказчику, нацеленному именно на локализацию, могут быть особенно интересны наши предложения по разработке и проектированию, так как эти этапы цикла создания изделия высоко ценятся при определении доли российского участия в локализованном производстве.

\section{Рост числа заказов в значительной степени связан с тем, что всё больше компаний приходят к нам для локализащии производства своей продукции}

Выполнение задач, поставленных в "Стратегии развития электронной промышленности Российской Федерации на период до 2030 года", должно привести к увеличению глубины локализации вплоть до ЭКБ. Как вы считаете, это поможет развитию рынка контрактного производства в России или, может быть, создаст какие-то препятствия?

Если говорить в целом об установке на замещение изделий зарубежного производства отечественными, то она, конечно, создает для нас дополнительные перспективы, поскольку обещает появление новых заказчиков. Собственно, этот процесс наблюдается уже сейчас: многие производители приходят к нам именно для локализации, отказываясь от изготовления своей продукции за рубежом. И это почти исключительно российские производители, настоящая работа с иностранными компаниями у нас только начинается.

Вопрос с ЭКБ не так однозначен. Сегодня отечественные компоненты используются довольно редко, в основном это ЭКБ для изделий ответственного применения. Закупка компонентов, произведенных в России, тоже часто создает проблемы - на складах, как правило, их нет, изготовления по заказу приходится долго ждать, да и цена у них выше, чем у импортных 
аналогов. Далее, в разработки общегражданского назначения закладывается обычно зарубежная ЭКБ, а изделия, подлежащие локализации, исходно построены исключительно на ней. Значит, надо либо организовывать выпуск полных аналогов, либо приглашать крупных иностранных производителей ЭКБ строить заводы в России - но пойдут ли они сюда, тем более в сегодняшней непростой обстановке?

А наша собственная ЭКБ нового поколения? В Стратегии записано требование о промышленном освоении кремниевой микроэлектроники с топологической нормой 28 нм, а затем и до 7-5 мм...

Что ж, время есть, можно ожидать, что это будет осуществлено. Тогда будут и разработки на такой компонентной базе. Но это относится к отечественным производителям, а зарубежные компании вряд ли станут использовать в своих проектах наши компоненты. Так что сомнительно, чтобы новое поколение отечественной ЭКБ смогло как-то помочь развитию локализации.

\section{По качеству российской ЭКБ бывают} нарекания. А бывает и наоборот: например, недавно в одно изделие мы поставили индуктивности отечественного производства, nотому что технологи отдали им предпочтение перед зарубеккными

\section{аналогами}

Есть ли претензии к российской ЭКБ по качеству, технологичности?

Да, по качеству бывают нарекания. А бывает и наоборот: например, недавно в одно изделие мы поставили индуктивности отечественного производства, потому что технологи отдали им предпочтение перед зарубежными аналогами. Правда, они плохо извлекались из ленты; надо сказать, проблемы с упаковкой характерны для нашей ЭКБ.

Где вы заказываете печатные платы (ПП), на которых собираете свои изделия?

Это зависит от сложности электронного узла и, соответственно, его платы. Поскольку мы специализируемся на сложных проектах, то платы у нас в основном производства Южной и Юго-Восточной Азии. Для типовых, сравнительно простых изделий платы можно приобрести и у российских производителей.

Нельзя ли уточнить, чего именно не могут обеспечить наши производители печатных плат?

Если говорить о возможностях производства, то у нас нет заводов, способных выпускать крупные серии, порядка сотен тысяч единиц. Кроме того, сроки: азиатские компании выполнят заказ за две-три недели, даже если это сложный проект, а наши назначат значительно более долгий срок.

С технической точки зрения, насколько я могу судить, пределом для серийной продукции наших заводов являются платы с шириной проводника / зазора 0,1/0,1 мм. Гибко-жесткие, гибридные платы, пП с микроотверстиями, с глухими отверстиями, технологии с несколькими циклами прессования - всё это только отрабатывается, иногда доступно как эксклюзивный продукт, но в устойчивом массовом производстве пока не освоено.

Как вы считаете, имеет ли смысл государству поддерживать это направление, развивать производство ПП?

Да, это нужно делать. Причем у профильных государственных органов это понимание присутствует, недаром же отечественные ПП, так же как собственная разработка, являются одним из весомых факторов при определении уровня локализации продукта.

Среднему и тем более малому бизнесу не под силу построить высокотехнологичный комплекс стоимостью в несколько десятков миллионов долларов. Несколько сравнительно крупных производств ПП, которые сейчас успешно работают, опираются на государственные инвестиции. Может быть, эту задачу возьмет на себя крупный бизнес; так или иначе, создание современного производства ПП должно опираться на мощную финансовую поддержку, чтобы пережить длительный период окупаемости и завоевать свою долю рынка, потеснив доминирующих сегодня зарубежных производителей.

Какую помощь от государства вы хотели бы получать для вашей компании?

Были бы полезны скидки по налогу на прибыль, на страховые отчисления и компенсации на проценты по кредитам при закупке оборудования в рамках программ развития производства. При сохранении нормальной экономической ситуации, при наличии заказчиков этих трех видов поддержки было бы достаточно для устойчивой работы и поддержания должного технологического уровня. 
Пользуетесь ли вы услугами фондов развития?

Нечасто. Вот сейчас 80\% затрат на участие в Embedded World нам компенсировал Российский экспортный центр. Была компенсация при закупке профессионального программного обеспечения Cadence Allegro, Sigrity и САМ350. В 2011 году получили помощь по процентам на кредиты для закупки оборудования. Пожалуй, это всё.

\section{Количество заказов на дизайн}

\section{постепенно увеличивается, и я думаю, что эта тенденция в дальнейшем будет только усиливаться}

Планируете ли вы развитие производства с капитальными инвестициями? Может быть, к этому стимулируют растущие требования заказчиков по микроминиатюризации? Не возникает ли необходимость замены или дополнения состава оборудования в связи с принятием регламента ТP ЕАЭС 037/2016, содержащего требования по бессвинцовой пайке?

Мы уже давно производим продукцию по бессвинцовой технологии, можем устанавливать все компоненты от типоразмера 01005 - до сих пор не было ситуации, чтобы мы не смогли собрать печатный узел так, как это нужно заказчику. Поэтому в данный момент в рассмотрении только точечные замены для повышения эффективности: думаем заменить одну из двух АОИ - ту, которая постарше; вероятно, будем менять самый первый наш установщик вместе с принтером.

Можно также отметить, что мы постоянно работаем над повышением степени автоматизации производства и управления им. Сейчас обновляем до последней версии систему SAP Business One, с которой давно работаем, чтобы минимизировать ошибки, автоматизировать работу с исправимыми дефектами и в целом ускорить производственный процесс.

Традиционный вопрос к контрактному производителю: каков уровень технологичности проектов, с которыми к вам приходят заказчики? Насколько их конструкторы учитывают возможности вашей технологии, оборудования?

У нас в основном квалифицированные заказчики. Проекты сложные, они работают с ними внимательно, стараются учитывать всё необходимое. Если что-то не соответствует нашим требованиям, мы даем рекомендации, заказчики довольно быстро с ними осваиваются, и проблем больше не возникает.
Кроме того, мы на систематической основе проводим семинары по DfM, что также способствует повышению качества поступающих к нам проектов.

Насколько среди российских компаний востребована услуга контрактного проектирования? Ведь это известная наша особенность - руководители стараются сосредоточить у себя весь цикл создания изделия, и уж тем более - этап разработки.

Наше дизайн-бюро работает уже больше 10 лет. Его специалисты высокопрофессиональны и обладают огромным опытом. Мы выполняем все требования заказчика, выдерживаем все технологические нормы, мы выравниваем шины и подсчитываем импедансы, проводим моделирование, и нередко бывает так, что, запустив проект в производство, сразу получаем работоспособный прототип.

Но, действительно, убедить заказчика перейти на аутсорсинг по дизайну печатных узлов непросто. Помимо желания полностью контролировать весь процесс, многие компании содержат большой штат проектировщиков и конструкторов, и это тоже становится препятствием при принятии решения о передаче разработки в стороннюю организацию.

Тем не менее всё больше заказчиков начинают понимать, что проектирование дешевле заказать нам, особенно если их проектные подразделения не имеют регулярной загрузки. Количество поступающих к нам заказов на дизайн постепенно увеличивается, и я думаю, что эта тенденция в дальнейшем будет только усиливаться.

\section{Каким вам видится ближайшее будущее компании?}

В последние три года мы показали хороший рост: по сравнению с 2016 годом в 2019-м объем продаж вырос в 2,5 раза, за один только 2019-й - на 50\%; мы вышли на постоянную работу в две смены. Надеемся, этот процесс будет продолжаться. Государственное стимулирование локализации производства должно помочь с отечественными заказами, ожидаем реальных результатов от наших усилий по привлечению зарубежных компаний. Пока непонятно, как сложится ситуация, но есть желание принять участие в выставке electronica в Мюнхене - там целый зал выделен под тематику контрактного производства.

В целом мы рассчитываем на развитие российского рынка контрактного производства вообще и нашей компании в частности.

\section{Спасибо за интересный рассказ.}

С А.Б.Соболевым беседовапи Ю.С. Ковалевский, Г.А. Логинова и В. Е.Мейлицев 



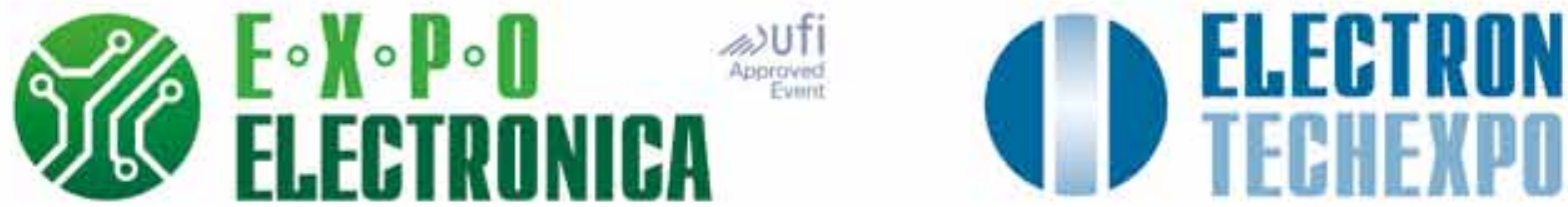

Крупнейшие выставки электронной промышленности в России и СНГ, которые охватывают полный цикл производства электроники

11-13 августа 2020

MOCKBa

МВЦ «Крокус Эксrio».
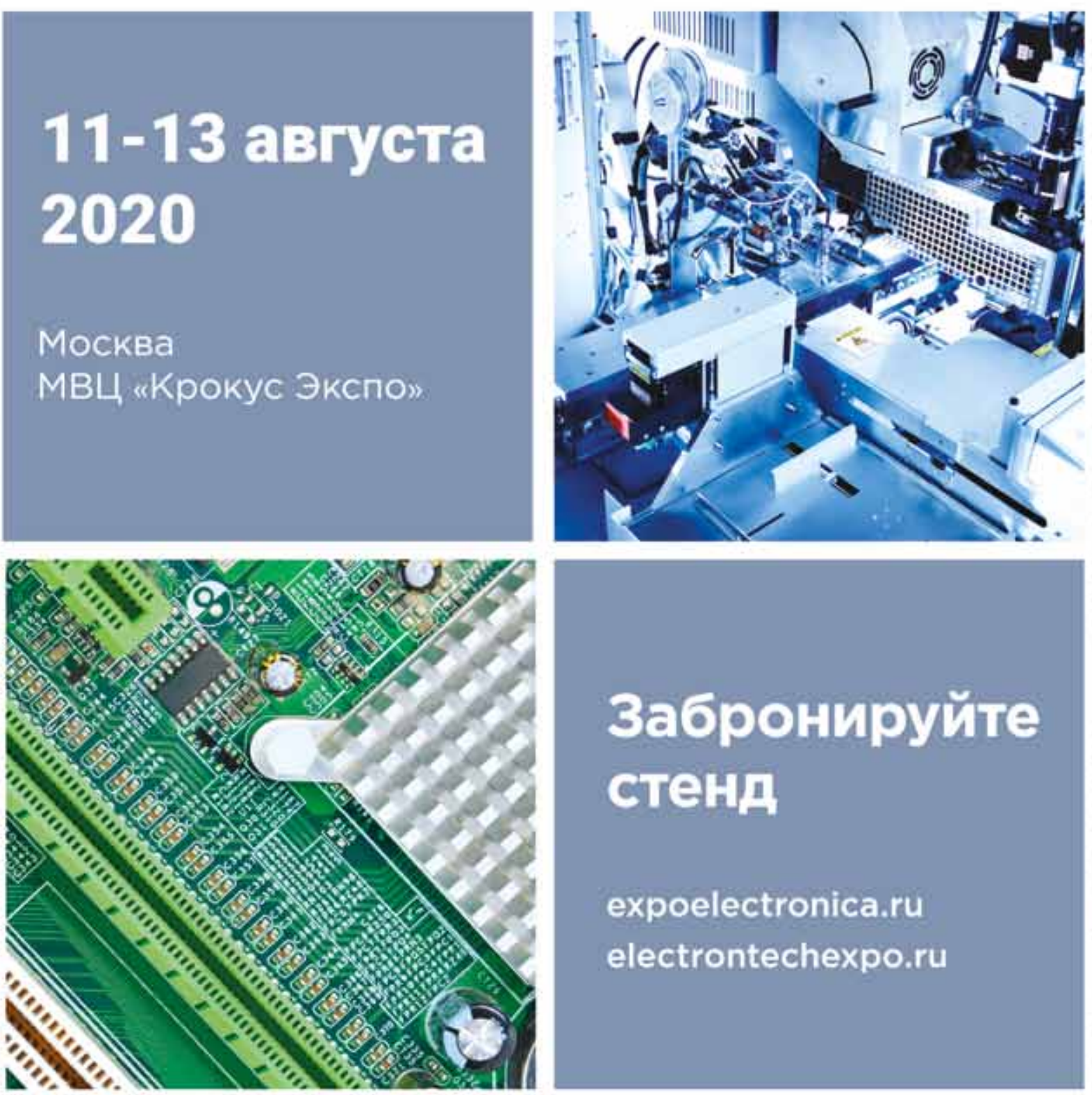

Забронируйте стенд

expoelectronica.ru electrontechexpo.ru

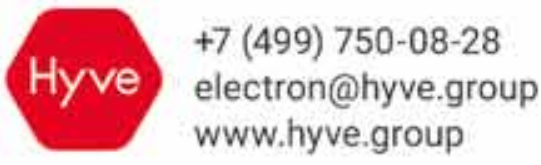

\section{Ваш компонент успеха!}

